\title{
Water is the Taste of Life - The Contribution of Metacognitive Guidance to Drinking-related Nutritional Literacy
}

\author{
Cohen Hagit, Zion Michal* \\ School of Education, Bar-Ilan University, Israel
}

*Corresponding Author: michal.zion@biu.ac.il

\section{ABSTRACT}

This study examined the contribution of metacognitive guidance to the development of drinking-related nutritional literacy(DNL). Metacognitive awareness promotes meaningful learning. Active involvement of students in metacognitive activities develops deep conceptual understanding. Childhood food and beverage consumption affects growth and can be a predictor of adult obesity, diabetes, and cardiovascular diseases. One of the factors that might improve food and beverage consumption is nutritional literacy. The research examined 225 students aged 9-11 and included a research and a control group. In both groups, students prepared and conducted an activity for students aged 6-8, as part of their science class. The activity sought to encourage the drinking of water and reducing the consumption of sweetened drinks. In the research group, the students received metacognitive guidance while preparing the activity. Changes in DNL in the areas of knowledge, attitudes, and behavior were tested by analysis of quantitative questionnaires. While there was no difference between the research and control groups in knowledge, the metacognitive guidance generated improvement in drinking-related attitudes and behavior. The improvement was seen both for everyday circumstances and at special occasions and emphasizes the great potential of expanding the relationship between metacognition and nutritional literacy.

KEY WORDS: sugar-sweetened beverages; metacognition; metacognitive guidance; nutritional literacy; water drinking

\section{INTRODUCTION}

$\mathbf{R}$ esearch has shown that children and adolescents have limited understanding about how food and drink affect health; their knowledge and understanding require improvement to support health-promoting dietary habits (Bullen, 2004). Most young adolescents (ages 9-13) find it difficult to believe that knowing health-related information can influence their health in the future. Consequently, adolescents have a low desire, and therefore, a limited likelihood to implement behavioral changes relating to health. It is, therefore, important to improve children's health literacy to raise their self-efficacy in the context of controlling their health behavior (Brown et al., 2007).

Research shows that metacognitive awareness promotes meaningful learning. It shows that the active involvement of students in metacognitive activities develops a deep conceptual understanding (Anderson and Nashon, 2007; Nashon and Anderson, 2004; Nielsen et al., 2009). Such an understanding is especially important when students face complex multivariate nutritional conflicts; they should be able to think critically about the information presented to them to offer applicable solutions. In this study, we examined the contribution of metacognitive guidance to drinking-related nutritional literacy (DNL).

\section{LITERATURE REVIEW}

\section{Health and Nutritional Literacy}

The development of health literacy enables individuals to increase control over their health (Nutbeam, 2008). Health literacy focuses on the enhancement of knowledge, attitudes, self-efficacy, and the confidence to take action toward improving personal and community health. Changing lifestyle behavior and living conditions are needed to effectuate this enhancement. With increased health literacy, children can actively participate in making decisions regarding their health and develop skills that will promote healthy behavior as adults (Borzekowski, 2009). One component of health literacy is nutritional literacy, defined as the level at which individuals can obtain, process, and understand nutritional information (Silk et al., 2008). The American Dietetic Association recently recognized this as a high priority issue (Zoellner et al., 2011).

The rise in obesity among children leads to a growing concern about the quality of food and drink consumed in childhood (Kaluski et al., 2008; Lissau et al., 2004; Reisch et al., 2011). The consumption of sugary drinks is far above the recommended amounts. Food intake in childhood correlates with increased risk for obesity, diabetes, and cardiovascular disease in adulthood. There are many factors that influence eating habits, including knowledge, attitudes, perceptions, and culture (Lakin and Littledyke, 2008; Lin et al., 2007).

Impact of Sugar-sweetened Beverages (SBSs) and Water Consumption on Health

Dental caries, diabetes, cardiovascular disease, fatty liver, and metabolic syndrome are just some of the problems associated with consumption of SSBs (Hu, 2013; Malik et al., 2010; Zoellner et al., 2014). In the quantities being consumed, SSBs 
contribute to the obesity epidemic by increasing the amount of energy consumed (Daniels and Popkin, 2010; Popkin et al., 2010). The current recommendation is to consume no more than $10 \%$ of one's calories from added sugar (McGuire, 2011). An international survey from 2005 to 2006 found that $41 \%$ of Israeli children aged 11 drink at least one SSB every day and that Israel is ranked second in the world in SSB consumption for this age group. The U.S. statistics for 11-year-old show consumption of at least one SSB cup a day among $29 \%$ of the girls and $35 \%$ of boys - ranking eighth in SSB consumption in countries surveyed (Currie, 2008).

However, interventions aimed at reducing SSB intake may inadvertently lead to the replacement of SSBs with other calorie-laden beverages such as whole milk or juice, resulting in negligible net benefit regarding calorie intake, particularly among younger children (Finkelstein et al., 2009). Consequently, along with the focus on reducing the consumption of SSBs, this research also aims to increase the amount of water that children consume. Preventing dehydration is central to continued survival. Insufficient water consumption has many drawbacks - dehydration affects concentration, short-term memory, and alertness; it also reduces physical performance. There is evidence of chronic moderate dehydration being a risk factor for various diseases (Popkin et al., 2010). Increasing water consumption through schoolbased interventions, in which water fountains for drinking were made accessible, has been shown to reduce the risk of obesity (Muckelbauer et al., 2009). These shifts in emphasis, which are aimed at reducing the consumption of SSBs and encouraging adequate water consumption, are important targets for public health interventions. When designing children's health promotion program, we should determine whether children are equipped with the appropriate tools to extract and apply health information that is accurate and meaningful to their own lives. They should also be encouraged to make accurate and meaningful connections between the health information they encounter and their own lives. In addition, children must be empowered to examine more critically the bias in health communications, thereby increasing their ability to participate actively in their own health decisions (Bhagat et al., 2018). In this paper, we propose to examine the contribution of metacognitive guidance to the development of children's DNL we base this on the assumption that metacognitive guidance can stimulate students to cognitive control and critical thinking. To the best of our knowledge, no existing study has examined the possible contribution of metacognitive guidance to the development of DNL.

\section{Metacognition}

Metacognition refers to the ability to reflect on, understand, and control one's cognitive processes (Schraw et al., 2006; Schraw and Dennison, 1994). Regulation of cognition is divided into the subprocesses of planning, process management, monitoring, debugging, and evaluation (Schraw and Dennison, 1994). The importance of developing metacognitive awareness among young students in the context of science teaching is widely recognized (Schraw et al., 2006; Zohar and Dori, 2011). We suggest that metacognition can play a central part in the development of nutritional literacy. Research indicates that metacognition promotes significant learning and that the active involvement of students in metacognitive activities develops deep conceptual understanding (Anderson and Nashon, 2007; Nashon and Anderson, 2004; Nielsen et al., 2009). This kind of understanding is particularly important for individuals facing complex and often conflicting nutritional choices on a daily basis. They must learn to consider the information presented and contemplate applicable solutions.

Furthermore, planning and monitoring improve the way students function in making decisions relating to their dietary choices (Chang, 2010; Lakin and Littledyke, 2008). In the field of health, high metacognition ability is associated with a higher level of constructive mental activity, including a thorough evaluation of information and situations, and a more in-depth evaluation of individual thought processes (Riva et al., 2015). We believe that metacognitive guidance, especially its regulation of cognition component, is central to the development of nutritional literacy and maybe successfully introduced and integrated into the field of nutritional education within the context of drinking.

This study aims to examine the contribution of drinkingrelated metacognitive guidance to the development of DNL. We hypothesize that while metacognitive guidance will not influence knowledge, it will influence attitudes that favor water drinking and decreasing SSB consumption, as well as selfefficacy for change. We also expect that students will develop healthy drinking habits by drinking more water, checking themselves for sufficient hydration (by examining urine color), and minimizing consumption of SSBs.

\section{METHODS}

\section{Research Design}

The research focused on the examination of metacognitive guidance as an independent variable. The purpose of metacognitive guidance was to orient students toward thinking in terms of regulation of cognition, all in the context of drinking enough water and fewer SSBs. The research examined DNL as the dependent variable, focusing on the ability of an individual to acquire, comprehend, and process nutritional information, and then make decisions about what and how much to drink. DNL was examined on three levels: Knowledge, attitude, and behavior.

\section{Participants}

The participant group included 225 students attending elementary schools in upper-middle-class communities; they were from 7 classes of $5^{\text {th }}$ and $6^{\text {th }}$ grades, where ages were 9 through the 11-year-old range. Classes were randomly assigned to metacognitive guidance $(n=128,56.9 \%$ - four classes $)$ and control ( $\mathrm{n}=97,43.1 \%$ - three classes). There were 114 boys $(50.6 \%)$ and 111 girls (49.4\%), with similar gender distribution by experimental condition $\left(\chi^{2}(1)=0.18, p=.674\right)$. The Chief 
Scientist of the Israel Ministry of Education approved carrying out the study in the chosen schools. The project was integrated as part of the science studies curriculum. If students or their parents objected, they did not participate in the project and failure to participate did not affect their final grade in science.

\section{Intervention}

During three science lessons, the students studied a "Nutritional Literacy about Drinking" learning unit, which emphasized the importance of sufficient water drinking and the hazards of SSB consumption. They also learned how to check whether they were drinking enough. The researcher delivered the three lessons to all classes of both the control group and intervention groups; the presentation was described as an expansion of the science curriculum. Then, over the course of 5 months, the students worked in groups of four, planning an activity that encouraged younger students, who were in the first through fourth grades, to drink more water and fewer SSBs. Each group was required to prepare a three-part activity.

The first part was a screenplay for a show or video clip that depicted daily situations and conveyed knowledge of two topics. Topic A, "Why you shouldn't drink too much SSB," explained the hazards of excessive consumption of high sugar beverages. The message conveyed was that drinking excessive amounts of SSBs result in dental health problems. Topic B asked "What do we gain when we drink sufficient water?" and explained that with sufficient water, we gain better concentration, along with success in studies and sports. In topic B, signs of dehydration were explained; illustrating, for example, how to determine if you drink sufficient amounts of water by observing the color of your urine.

The second part of the activity was a game to remind the younger students what they have learned in the first part while checking whether they understood it. The third part of the activity was the presentation of a souvenir to the younger children, to help them remember the activities, they experienced and shared the messages with their parents. An example of a souvenir is a magnet with a slogan about how to know when they had consumed enough water. The learning process peaked with a health day in which the upper-grade students presented the younger students with the activities they had developed. The learning process was part of the relevant science curriculum and the yearly schedule of the participating schools.

The metacognitive guidance included regulation of cognition instructions (Mevarech and Kramarski, 1997; Schraw and Nietfeld, 1998). The aim was to encourage reflective thinking about the learning process. The metacognitive guidance focused on DNL aspects (Appendix A). To eliminate different teacher influences, a single health educator taught all the teams. Table 1 shows the differences between the two groups. The intervention group filled in a metacognitive guidance questionnaire that was not administered to the control group. Students of the intervention group were also taught by the researcher to monitor their progress.

\section{Research Tools}

We developed two research tools to examine DNL. The first was a nutritional literacy questionnaire that examined knowledge, attitudes about the importance of drinking water and reducing SSB consumption, and self-efficacy. The second was a questionnaire that examined healthy drinking habits, i.e., behavior, in the context of drinking water and SSBs.

1. DNL questionnaire. This questionnaire was based on both Diamond (2007) Nutritional Literacy Scale and Balin (2009) SSB questionnaire. The questionnaire includes items regarding drinking-related knowledge, attitudes, and self-efficacy about drinking and matches the terminology of health literacy (Nutbeam, 2008). The questionnaire included 35 items, of which 14 are knowledge questions, 15 represent attitudes about drinking, and six represent self-efficacy regarding drinking (Appendix B).

a. "Drinking-related knowledge" questions were evaluated and rated on a correct or incorrect basis. We converted a $0-100$ score to provide a percentage. "Attitudes about drinking"

b. "Self-efficacy about drinking" questions were rated on a 5-point agreement scale from "not at all true" (1) to "extremely true" (5). Internal consistencies were generally acceptable for knowledge $(\alpha=0.65)$, attitudes $(\alpha=0.84)$, and self-efficacy $(\alpha=0.64)$.

2. The drinking questionnaire was based on "Guidelines for Beverage Consumption" (Popkin et al., 2006), a CDC report (Brener, 2011) and an SSB questionnaire (Balin, 2009). It included in the study:

a. One item regarding bringing water to school, where Yes is rated as 1 and No as 0

b. One item regarding how much water the student drinks at school daily

c. Thirteen items concerning the quality of drinking at home and at events and special occasions. These items were rated on a $0-5$ scale, where 0 indicates does not drink, 1 indicates sweet drinks, 2 indicates sweet drinks and another drink that is not water, 3 indicates water and sweet drinks, 4 indicates water and another drink that is not an SSB, and 5 indicates water. A principal components factor analysis of these 13 items, with varimax rotation, has yielded two factors that explain $50.7 \%$ of the variance. The first factor: "Quality of everyday drinking" has six items, with eigenvalue $=4.68,36 \%$ of the explained variance, and item loadings that range between 0.68 and 0.77 . Internal consistency: $\alpha=0.84$. The second factor: "Quality of drinking on special occasions," has seven items, with eigenvalue $=1.92,14.8 \%$ of the explained variance, and item loadings that range between 0.46 and 0.71. Internal consistency: $\alpha=0.81$ (Appendix C).

We defined both factors with item means; higher scores indicate consumption of a better-quality liquid. All students filled out the two questionnaires online, before and after the intervention. 


\begin{tabular}{|c|c|c|}
\hline Study stage & Intervention group (Meta) & Control group \\
\hline Three science lessons & \multicolumn{2}{|c|}{$\begin{array}{l}\text { All students studied a "Nutritional Literacy about Drinking" learning unit that emphasized the importance of sufficient } \\
\text { water drinking and the hazards of SSB consumption. The researcher taught this learning unit in all classes involved in } \\
\text { the study }\end{array}$} \\
\hline 5 months of bi-weekly meetings & \multicolumn{2}{|c|}{$\begin{array}{l}\text { The students worked in groups of four, planned an activity that encouraged younger students, from } 1^{\text {st }} \text { to } 4^{\text {th }} \text { grades, to } \\
\text { drink more water and fewer SSBs. Each group was asked to prepare a three-part activity }\end{array}$} \\
\hline \multirow[t]{2}{*}{$\begin{array}{l}\text { During bi-weekly meetings with } \\
\text { the researcher }\end{array}$} & \multicolumn{2}{|c|}{$\begin{array}{l}\text { In each meeting with the researcher students presented the tasks they prepared, received new tasks for the next } \\
\text { meeting, and found solutions to various difficulties that came up while preparing the tasks }\end{array}$} \\
\hline & $\begin{array}{l}\text { Students of the intervention group also received metacognitive guidance, } \\
\text { learned to monitor themselves, to examine the adequacy of the tasks they } \\
\text { had prepared during every meeting, and to adjust where needed }\end{array}$ & - \\
\hline $\begin{array}{l}\text { Metacognitive guidance } \\
\text { questionnaire - for the } \\
\text { intervention group only }\end{array}$ & $\begin{array}{l}\text { Guidance, including metacognitive questions, was presented to students } \\
\text { at three different times during the learning process: A month after, they } \\
\text { began to prepare the activity, a month before conducting the activity, and } \\
\text { finally, after completing the activity. The aim was to encourage reflective } \\
\text { thinking about the learning process*. The metacognitive guidance was } \\
\text { based on DNL aspects }\end{array}$ & $\begin{array}{l}\text { Control group students did not fill out a } \\
\text { metacognitive guidance questionnaire }\end{array}$ \\
\hline
\end{tabular}

*Appendix A

A pilot research activity was carried out among 30 students, the results of which led to improvements in the metacognitive guidance and the questionnaires.

\section{Data Analysis}

Changes in knowledge and attitudes about drinking, in selfefficacy, and in the quality of everyday drinking were examined with repeated measures of analysis of covariance. In this procedure, we used group (with the between-subjects variable) and time (with the within-subjects variable), as independent variables and controlled for grade level. Estimated marginal means were used as post hoc tests to interpret significant group by time interactions. We examined changes in the quality of drinking on special occasions, with an analysis of variance of adjusted residual gains due to the initial significant group difference.

\section{RESULTS}

The Impact of Metacognitive Guidance on Drinking-related Knowledge, Attitudes, and Self-efficacy about Drinking

Table 2 shows the results of changes in drinking-related knowledge, attitudes, and self-efficacy about drinking. Repeated measures of analyses of covariance showed that when compared to pre-intervention scores, drinking-related knowledge increased similarly in both groups, beyond actual grade level, from $\mathrm{M}=67.7(\mathrm{SE}=1.19)$ to $\mathrm{M}=81.3(\mathrm{SE}=0.86)$. Attitudes about drinking have improved significantly in both groups, but to a greater extent in the meta-guidance group, where scores increased from $\mathrm{M}=3.82(\mathrm{SE}=0.05)$ to $\mathrm{M}=4.15(\mathrm{SE}=0.05)\left(\mathrm{p}<0.001, \eta^{2}=0.146\right)$, while in the control group scores increased from $\mathrm{M}=3.80(\mathrm{SE}=0.06)$ to $\mathrm{M}=3.94(\mathrm{SE}=0.06),\left(\mathrm{p}=0.019, \eta^{2}=0.025\right)$. The group by time interaction is significant $(\mathrm{p}=0.028)$ and yet changes in both groups are significant as well. That is, both groups have improved, yet change in the intervention group $\left(\eta^{2}=0.146\right)$ is higher than in the control group $\left(\eta^{2}=0.025\right)$. Self-efficacy about drinking scores increased from $\mathrm{M}=3.88(\mathrm{SE}=0.06)$ to
$\mathrm{M}=4.23(\mathrm{SE}=0.05)$ in the meta-guidance group $(\mathrm{p}<0.001$, $\eta^{2}=0.179$ ), while no significant change was evident in the control group $\left(\mathrm{p}=0.084, \eta^{2}=0.014\right)$.

\section{The Impact of Metacognitive Guidance on the Drinking} Habits of Students

Drinking water in school: The students consumed an average of $0.7 \mathrm{~L}$ of water a day at school. The median drinking quantity is $0.5 \mathrm{~L}$, with $2.7 \%$ of the students not drinking water in school, $72.7 \%$ drinking from $0.25 \mathrm{~L}$ to a $0.75 \mathrm{~L}$, and the rest $24.6 \%$ drinking $1 \mathrm{~L}$ of water or more. No time or group differences were found in this index.

Table 3 presents the results of the changes in the quality of everyday drinking and special occasion drinking. The quality of everyday drinking increased significantly in the meta-guidance group $\left(\mathrm{p}<0.001, \eta^{2}=0.058\right)$ from $\mathrm{M}=3.97(\mathrm{SE}=0.11)$ to $\mathrm{M}=4.34(\mathrm{SE}=0.10)$ (Table 3). It decreased in the control group from $\mathrm{M}=4.04(\mathrm{SE}=0.13)$ to $\mathrm{M}=3.71(\mathrm{SE}=0.12)(\mathrm{p}=0.008$, $\eta^{2}=0.032$ ). Changes in the quality of special occasion drinking were examined with adjusted residual gains, due to the initial significant group difference. The changes were significantly different between the groups: A positive gain of $\mathrm{M}=0.25$ ( $\mathrm{SE}$ $=0.08)$ in the meta-guidance group and a decrease in the control group $(\mathrm{M}=-0.36, \mathrm{SE}=0.10)\left(\mathrm{p}<0.001, \eta^{2}=0.093\right)$.

We should note that while we have not been able to show an increase of water consumption in school, the statistically significant improvement in the quality of everyday and special-occasion drinking in the intervention group does reflect an increase in water consumption and a decrease in SSB consumption.

\section{DISCUSSION}

This study set out to examine the impact of metacognitive guidance about DNL by considering several measures of knowledge, attitudes, self-efficacy, and drinking habits of students. 
Table 2: The impact of metacognitive guidance on drinking-related knowledge, attitudes, and self-efficacy about drinking (means, standard deviations, and F values for DNL by group and time $[n=225]$ )

\begin{tabular}{|c|c|c|c|c|c|c|}
\hline \multirow[t]{5}{*}{ DNL categories } & \multirow{2}{*}{\multicolumn{2}{|c|}{$\begin{array}{c}\text { Metacognitive guidanc } \\
\end{array}$}} & \multicolumn{2}{|c|}{ Control } & \multirow{2}{*}{$\begin{array}{c}\mathrm{F}_{\text {Time }}(1,223) \\
(\mathrm{p})\end{array}$} & \multirow{2}{*}{$\frac{F_{\text {Time } \times \text { Meta }}(1,223)}{(p)}$} \\
\hline & & & & & & \\
\hline & \multicolumn{2}{|c|}{ (SD) } & \multicolumn{2}{|c|}{ (SD) } & $\left(\eta^{2}\right)$ & $\left(\eta^{2}\right)$ \\
\hline & \multicolumn{2}{|c|}{$(n=128)$} & \multicolumn{2}{|c|}{$(n=97)$} & & \\
\hline & Pre & Post & Pre & Post & & \\
\hline Knowledge about drinking & $\begin{array}{c}66.61 \\
(18.06)\end{array}$ & $\begin{array}{c}81.41 \\
(12.35)\end{array}$ & $\begin{array}{c}69.22 \\
(17.16)\end{array}$ & $\begin{array}{c}81.21 \\
(12.82)\end{array}$ & $\begin{array}{c}142.66 \\
(p<0.001) \\
\left(\eta^{2}=0.400\right)\end{array}$ & $\begin{array}{c}0.03 \\
(p=0.856) \\
\left(\eta^{2}=0.001\right)\end{array}$ \\
\hline Attitudes about drinking & $\begin{array}{c}3.83 \\
(0.57)\end{array}$ & $\begin{array}{c}4.15 \\
(0.50)\end{array}$ & $\begin{array}{c}3.80 \\
(0.65)\end{array}$ & $\begin{array}{c}3.94 \\
(0.62)\end{array}$ & $\begin{array}{c}33.29 \\
(p<0.001) \\
\left(\eta^{2}=0.134\right)\end{array}$ & $\begin{array}{c}4.90 \\
(p=0.028) \\
\left(\eta^{2}=0.022\right)\end{array}$ \\
\hline Self-efficacy about drinking & $\begin{array}{c}3.88 \\
(0.69)\end{array}$ & $\begin{array}{c}4.23 \\
(0.55)\end{array}$ & $\begin{array}{c}4.11 \\
(0.57)\end{array}$ & $\begin{array}{c}4.21 \\
(0.61)\end{array}$ & $\begin{array}{c}33.84 \\
(p<0.001) \\
\left(\eta^{2}=0.136\right)\end{array}$ & $\begin{array}{c}10.24 \\
(p=0.002) \\
\left(\eta^{2}=0.045\right)\end{array}$ \\
\hline
\end{tabular}

Drinking-related knowledge about drinking - scale 0-100, attitudes about drinking, self-efficacy about drinking - scale 1-5

Table 3: Change in the quality of everyday drinking and special-occasion drinking (means, standard deviations, and $\mathrm{F}$ values for quality of everyday and special occasion drinking by group and time $[n=225]$ )

\begin{tabular}{|c|c|c|c|c|c|c|}
\hline \multirow[t]{5}{*}{ Drinking habits categories } & \multicolumn{2}{|c|}{ Metacognitive guidance } & \multicolumn{2}{|c|}{ Control } & \multirow{2}{*}{$\begin{array}{c}F_{\text {Time }}(1,223) \\
(p)\end{array}$} & \multirow{2}{*}{$\begin{array}{c}\mathrm{F}_{\text {Time } \times \text { Meta }}(1,223) \\
(\mathrm{p})\end{array}$} \\
\hline & & & & & & \\
\hline & \multicolumn{2}{|c|}{ (SD) } & \multicolumn{2}{|c|}{ (SD) } & $\left(\eta^{2}\right)$ & $\left(\eta^{2}\right)$ \\
\hline & \multicolumn{2}{|c|}{$(n=128)$} & \multicolumn{2}{|c|}{$(n=97)$} & & \\
\hline & Pre & Post & Pre & Post & & \\
\hline Quality of everyday drinking & $\begin{array}{c}3.97 \\
(1.18)\end{array}$ & $\begin{array}{c}4.34 \\
(1.03)\end{array}$ & $\begin{array}{c}3.97 \\
(1.29)\end{array}$ & $\begin{array}{c}3.74 \\
(1.32)\end{array}$ & $\begin{array}{c}0.07 \\
(0.794) \\
\left(\eta^{2}=0.001\right)\end{array}$ & $\begin{array}{c}19.03 \\
(p<0.001) \\
\left(\eta^{2}=0.082\right)\end{array}$ \\
\hline Quality of drinking on special occasions & $\begin{array}{c}2.49 \\
(1.01)\end{array}$ & $\begin{array}{c}2.76 \\
(1.07)\end{array}$ & $\begin{array}{c}3.06 \\
(1.67)\end{array}$ & $\begin{array}{c}2.28 \\
(0.97)\end{array}$ & $\begin{array}{c}9.09 \\
(\mathrm{p}=0.003) \\
\left(\eta^{2}=0.041\right)\end{array}$ & $\begin{array}{c}21.84 \\
(p<0.001) \\
\left(\eta^{2}=0.093\right)\end{array}$ \\
\hline
\end{tabular}

Scale $1-5$

As hypothesized, we observed an increase in knowledge relating to nutritional literacy in both research groups, with no significant difference between them. We also observed an increase in attitudes relating to the importance of drinking water and reducing SSB consumption. We found a more significant increase in this index among students who received metacognitive guidance when compared to the control group. This result confirmed the research hypothesis. The change in attitudes means that students assign more importance to read nutrition labels. Students found it important to be informed about the potential harm resulting from dehydration, drinking SSBs, and the benefits of drinking enough water. If before the intervention, these issues were of no interest or significance to them; after the intervention, the students regarded them with great importance. The increase in attitudes can be explained by the application of critical thinking among students who received drinking-related metacognitive guidance. Earlier research established the connection between metacognitive guidance and critical thinking. Metacognitive skills, such as planning and evaluation, are essential tools in the development of critical thinking skills (Fahim and Dorrimanesh, 2015; Magno, 2010; Mall-Amiri and Ahmadi, 2014).

Although we observed an increase in self-efficacy, that increase was achieved only among the students who received metacognitive guidance. These results support the research hypothesis. In the field of health decisions, self-efficacy is thought to be a link between knowledge and behavior. Selfefficient people seek relevant information for their own health and they have confidence that they will make the right decision to preserve their health (Riva et al., 2015). Greater self-efficacy indicates greater confidence in one's ability to affect change. It appears that students who acquired metacognitive awareness felt a greater desire to affect change because they have a better understanding of the expected rewards. The students felt more confident in their ability to implement the change because they learned how to question whether their choices actually help them drink more water and fewer SSBs. 
Behavior drinking habits of students: The quality of everyday and special-occasion drinking was improved only among students who received metacognitive guidance. These results corroborate the research hypothesis. This is a pioneering study illustrating that metacognitive guidance can bring about changes in drinking-related behavior. One possible explanation for finding improvement in the drinking habits among students who received metacognitive guidance is the idea that students might have used metacognitive awareness as a tool for changing their behavior.

Health-related sociocognitive models, such as the "health belief model" and "theory of planned behavior," suggest that to have a shift in behavior, a person needs to have motivation. The source of motivation is knowing the advantages of making the change and the tools to make the change (Conner and Norman, 1996; Icek, 1991). Among the students receiving metacognitive guidance, a more significant improvement in attitudes about the importance of drinking more water and fewer SSBs may indicate greater motivation to change their behavior. Greater motivation may encourage students to find the solutions; they require to make the change. Metacognitive learners can recognize when they are effectively learning; they employ the use of additional strategies to control or monitor their motivation (Alexander, 2008).

Another explanation for the change in drinking-related behavior among students receiving metacognitive guidance can be drawn from studies showing that metacognitive awareness promotes meaningful learning (Anderson and Nashon, 2007; Nashon and Anderson, 2004; Nielsen et al., 2009). This level of understanding may have assisted students to critically consider what they should drink and, as a result, to change their behavior. A third explanation for the improvement of students' drinking-related behavior may be linked to the fact that students receiving metacognitive guidance showed better performance on other components of DNL, specifically knowledge, attitude, and self-efficacy. In a recently published article, the interaction of self-efficacy and health literacy significantly predicted fruit and vegetable consumption and weekly exercise (Guntzviller et al., 2017). Thus, the findings of a significant increase in self-efficacy among students receiving metacognitive guidance may explain part of the improvement in the quality of everyday and special occasion drinking.

Contrary to our hypothesis, we did not observe a significant change between pre- and post-intervention in the quantity of water consumed at school. The students drink an average of 0.7 L daily, leading us to conclude that the majority of the students were already consuming enough water in school. Perhaps, there was not much room for improvement in this aspect of the study. Examining a group that was initially drinking less water would have perhaps shown the improvement; we were anticipating.

\section{Research Limitations}

The subjects' relatively strong socioeconomic backgrounds may have influenced their basic nutritional literacy. The effects of an intervention among communities of lower socioeconomic background who drink more soft drinks should be examined.
Doing this may have produced more significant results. No long-term observation was carried out to examine whether the changes in attitude and behavior. Future research is advised to follow-up with the students a year after the intervention, to see whether its effects last.

\section{CONCLUSION}

This research shows that metacognitive guidance can generate changes in drinking-related behavior. Metacognitive guidance has contributed significantly to an improvement in nutritional literacy that is focused on self-efficacy and behavior levels. We observed improvements in everyday and special occasion drinking. These results emphasize the great potential of the relationship between metacognition and nutritional literacy to be subjects of future investigation.

\section{ACKNOWLEDGMENTS}

We would like to thank Ori Stav and Ze'ev Kaplan for their editorial assistance and Edna Guttmann for her statistical assistance.

This research was part of the Ph.D. thesis of the first author.

\section{REFERENCES}

Alexander, P.A. (2008). Why this and why now? Introduction to the special issue on metacognition, self-regulation, and self-regulated learning Education Psychological Reviews, 20, 369-372.

Anderson, D., \& Nashon, S.M. (2007). Predators of knowledge construction: Interpreting students' metacognition in an amusement park physics program. Science Education, 91(2), 298-320.

Balin, A. (2009). Influences on School-age Children's Milk and Soft Drink Intake (Doctoral Dissertation). Ohio: Case Western Reserve University.

Bhagat, K., Howard, D.E., \& Aldoory, L. (2018). The relationship between health literacy and health conceptualizations: An exploratory study of elementary school-aged children. Health Communication, 33(2), 131-138.

Borzekowski, D.L. (2009). Considering children and health literacy: A theoretical approach. Pediatrics, 124 Suppl 3, S282-288.

Brener, N.D. (2011). Beverage consumption among high school studentsUnited States, 2010. Morbidity and Mortality Weekly Report, 60, 778.

Brown, S.L., Teufel, J.A., \& Birch, D.A. (2007). Early adolescents perceptions of health and health literacy. Journal of School Health, $77(1), 7-15$.

Bullen, K. (2004). Changing children's food and health concepts: A challenge for nutrition education. Education and Health, 22(4), 51-55.

Chang, L.C. (2010). Health literacy, self-reported status and health promoting behaviours for adolescents in Taiwan. Journal of Clinical Nursing, 20(1-2), 190-196.

Conner, M., \& Norman, P. (1996). Predicting Health Behavior. Search and Practice with Social Cognition Models. Buckingham, UK: Open University Press.

Currie, C. (2008). Inequalities in Young People's Health: HBSC International Report from the 2005/2006 Survey. Copenhagen: World Health Organization.

Daniels, M.C., \& Popkin, B.M. (2010). Impact of water intake on energy intake and weight status: A systematic review. Nutrition Review, 68(9), 505-521.

Diamond, J.J. (2007). Development of a reliable and construct valid measure of nutritional literacy in adults. Nutrition Journal, 6, 5-11.

Fahim, M., \& Dorrimanesh, P. (2015). Do better critical thinkers use metacognitive learning strategies more frequently. International Journal of English Language, Literature and Humanities, 3(4), 800-818.

Finkelstein, E.A., Trogdon, J.G., Cohen, J.W., \& Dietz, W. (2009). Annual 
medical spending attributable to obesity: Payer-and service-specific estimates. Health Affairs, 28(5), w822-w831.

Guntzviller, L.M., King, A.J., Jensen, J.D., \& Davis, L.A. (2017). Selfefficacy, health literacy, and nutrition and exercise behaviors in a low-income, Hispanic population. Journal of Immigrant and Minority Health, 19(2), 489-493.

Hu, F.B. (2013). Resolved: There is sufficient scientific evidence that decreasing sugar-sweetened beverage consumption will reduce the prevalence of obesity and obesity-related diseases. Obesity Reviews, 14(8), 606-619.

Icek, A. (1991). The theory of planned behavior. Organizational Behavior and Human Decision Processes, 50(2), 179-211.

Kaluski, D.N., Mazengia, G.D., Shimony, T., Goldsmith, R., \& Berry, E.M. (2008). Prevalence and determinants of physical activity and lifestyle in relation to obesity among schoolchildren in Israel. Public Health Nutrition, 12, 774-782.

Lakin, L., \& Littledyke, M. (2008). Health promoting schools: Integrated practices to develop critical thinking and healthy lifestyles through farming, growing and healthy eating. International Journal of Consumer Studies, 32(3), 253-259.

Lin, W., Yang, H.C., Hang, C.M., \& Pan, W.H. (2007). Nutrition knowledge, attitude, and behavior of Taiwanese elementary school children. Asia Pacific Journal of Clinical Nutrition, 16 Suppl 2, 534-546.

Lissau, I., Overpeck, M.D., Ruan, W.J., Due, P., Holstein, B.E., \& Hediger, M.L. (2004). Body Mass index and overweight in adolescents in 13 European countries, Israel, and the United States. Arch Pediatrician Adolescent Medience, 158(1), 27-33.

Magno, C. (2010). The role of metacognitive skills in developing critical thinking. Metacognition and Learning, 5(2), 137-156.

Malik, V.S., Popkin, B.M., Bray, G.A., Després, J.P., Willett, W.C., \& Hu, F.B. (2010). Sugar-sweetened beverages and risk of metabolic syndrome and Type 2 diabetes a meta-analysis. Diabetes Care, 33(11), 2477-2483.

Mall-Amiri, B., \& Ahmadi, Z. (2014). The relationship between EFL learners' critical thinking and metacognitive strategies. International Journal of Language Learning and Applied Linguistics World, 5(1), 488-505.

McGuire, S. (2011). US department of agriculture and US department of health and human services, dietary guidelines for Americans, 2010. Washington, DC: US government printing office, January 2011. Advances in Nutrition: An International Review Journal, 2(3), 293-294.

Mevarech, Z.R., \& Kramarski, B. (1997). IMPROVE: A multidimensional method for teaching mathematics in heterogeneous classrooms. American Educational Research Journal, 34(2), 365-394.

Muckelbauer, R., Libuda, L., Clausen, K., Toschke, A.M., Reinehr, T., \& Kersting, M. (2009). Promotion and provision of drinking water in schools for overweight prevention: Randomized, controlled cluster trial.
Pediatrics, 123(4), e661-667.

Nashon, S.M., \& Anderson, D. (2004). Obsession with "g": A metacognitive reflection of a laboratory episode. Alberta Science Educational Journal, 36(2), 39-44.

Nielsen, W.S., Nashon, S., \& Anderson, D. (2009). Metacognitive engagement during field-trip experiences: A case study of students in an amusement park physics program. Journal of Research in Science Teaching, 46(3), 265-288.

Nutbeam, D. (2008). The evolving concept of health literacy. Social Science Medicine, 67(12), 2072-2078.

Popkin, B.M., Armstrong, L.E., Bray, G.M., Caballero, B., Frei, B., \& Willett, W.C. (2006). A new proposed guidance system for beverage consumption in the United States. American Journal of Clinical Nutrition, 83(3), 529-542.

Popkin, B.M., D'Anci, K.E., \& Rosenberg, I.H. (2010). Water, hydration, and health. Nutrition Review, 68(8), 439-458.

Reisch, L.A., Gwozdz, W., \& Beckmann, S. (2011). Consumer behavior in childhood obesity research and policy. In: Epidemiology of Obesity in Children and Adolescents. New York: Springer. p431-454.

Riva, S., Antonietti, A., Iannello, P., \& Pravettoni, G. (2015). What are judgment skills in health literacy? A psycho-cognitive perspective of judgment and decision-making research. Patient Preference and Adherence, 9, 1677-1686.

Schraw, G., \& Dennison, R.S. (1994). Assessing metacognitive awareness. Contemporary Educational Psychology, 19(4), 460-475.

Schraw, G., \& Nietfeld, J. (1998). A further test of the general monitoring skill hypothesis. Journal of Educational Psychology, 90(2), 236-248.

Schraw, G., Crippen, K.J., \& Hartley, K. (2006). Promoting self-regulation in science education: Metacognition as part of a broader perspective on learning. Research in Science Education, 36(1-2), 111-139.

Silk, K.J., Sherry, J., Winn, B., Keesecker, N., Horodynski, M.A., \& Sayir, A. (2008). Increasing nutrition literacy: Testing the effectiveness of print, web site, and game modalities. Journal of Nutrition Education and Behavior, 40(1), 3-10.

Zoellner, J., Chen, Y., Davy, B.M., You, W., Hedrick, V.E., Corsi, T., \& Estabrooks, P. (2014). Talking health, a pragmatic randomized-controlled health literacy trial targeting sugar-sweetened beverage consumption among adults: Rationale, design and methods. Contemporary Clinical Trials, 37(1), 43-57.

Zoellner, J., You, W., Connell, C., Smith-Ray, R.L., Allen, K., Tucker, K.L., Estabrooks, P. (2011). Health literacy is associated with healthy eating index scores and sugar-sweetened beverage intake: Findings from the rural Lower Mississippi Delta. Journal of the American Dietitian Association, 111(7), 1012-1020.

Zohar, A., \& Dori, Y.J. (2011). Metacognition in Science Education: Trends in Current Research. Dordrecht, The Netherlands: Springer Science and Business Media. 


\section{APPENDIX}

\section{Appendix A: Examples of drinking-related metacognitive guidance questions}

Planning

1a. Consider the activity you planned - what were your goals?

Process

2a. How did you organize to prepare the activity?

Evaluation during the process

3a. Describe a moment when you stopped to consider - whether this activity really makes kids drink more water

3c. What were your doubts? What did you decide? How was this decision made?

Spotting difficulties

4a. Where 1 is not true and 5 is very true, mark the choice that applies to you with regard to the following statement: I did not experience difficulties preparing the activity

$\begin{array}{lllllll} & 1 & 2 & 3 & 4 & 5 & \\ \text { Not true } & 0 & 0 & 0 & \circ & \circ & \text { Very true }\end{array}$

Evaluating the activity

5b. Explain: Why would the kids who participated in the activity drink more water?

6c. Explain: Why would the kids who participated in the activity not drink fewer soft drinks?

8. If you had to prepare the activity all over again - what would you do differently?

Self-evaluation

9c. Why has preparation of the activity for first and second graders affected your behavior? Elaborate.

\section{Appendix B: Nutritional literacy by subject questionnaire}

Examples used for knowledge questions.

Drinking sugar-sweetened beverages can cause caries (cavities).

Dehydration as a result of water deficiency can affect concentration, memory, alertness, and achievements at school.

The simplest way to know if we have had enough to drink is to examine the color of our urine.

Examples for attitude questions

It is important to drink enough so that we do not dehydrate.

It is important for me to know if I have drunk enough.

It is important for me to know the hazards of drinking sugar-sweetened beverages.

Examples for self-efficacy questions

I can solve most problems if I properly put my mind to it.

I can tell if I have had enough water.

I choose what kinds of drinks I drink at home.

\section{Appendix C: Drinking questionnaire}

Answer each question with one of the beverages below:

Diet beverages, natural fruit juices, sugar-sweetened beverages (fizzy or flat), milk-based beverages (chocolate, mocha, etc.), water (and soda water), and other beverages

Examples for questions about everyday drinking quality

At the table during mealtime we usually serve:

I usually drink:

Special occasion drinking quality

During the holiday or some other festive dinner, I drink:

Dining out - the drink I would usually order is:

At events I usually drink: 